\section{§1. Effects of Post-weld Heat Treatment Conditions on Hardness, Microstructures and Impact Properties of Vanadium Alloys}

Nagasaka, T., Muroga, T., Grossbeck, M.L., King, J.F. (Oak Ridge Natl. Lab., USA),

Yamamoto, T. (IMR, Tohoku Univ.)

Welding is a key technology for the low-activation vanadium alloys to realize a large component for fusion reactors. Gus-tungsten-arc (GTA) weld joints produced from NIFS-HEAT-1, a Japanese reference V-4Cr-4Ti alloy with low oxygen level, exhibited better impact properties than similar weld joints produced from the US large heat. The results indicated that the impact property significantly improved by reducing solute oxygen content in the weld metal. Post-weld heat treatment (PWHT) is known to improve the impact property of the weld joint. Systematic study of hardness and microstructural evolution with the heat treatment is necessary to investigate mechanism of the PWHT effect. The purpose of this study is to estimate PWHT effects on hardness, microstructure and impact property for the mechanistic understanding.

Gas-tungsten-arc weld joints were made from the $\mathrm{V}-4 \mathrm{Cr}-4 \mathrm{Ti}$ alloy products, which were designated as NIFS-HEAT-1 (NH1), HP and US832665 (US) by 6-pass welds. Impurity levels of the weld joints are shown in Table 1. Oxygen level in weld metal varied with combination of the plate and the filler wire. All the weld joints were contaminated with hydrogen during GTA welding. PWHT was made at $473-1273 \mathrm{~K}$ for 1 hour. As shown in Table 1, hydrogen concentration was reduced from 58 wppm to 1 wppm by PWHT at $673 \mathrm{~K}$. Distribution of Vickers hardness around weld metal was measured with the load of $500 \mathrm{gf}$ for 30 sec. Transmission electron microscopy (TEM) was conducted at the center of weld metal. Charpy impact test with $1 / 3$ size specimens $(3.3 \times 3.3 \times 25.4 \mathrm{~mm})$ was performed after PWHT at 673, 1073 and $1173 \mathrm{~K}$. The V-notch on the Charpy specimens was 30 degree in included angle and $0.66 \mathrm{~mm}$ in depth.

Table 1 Impurity levels of gas-tungsten-arc weld joints of $\mathrm{V}-4 \mathrm{Cr}-4 \mathrm{Ti}$ alloys (wppm).

\begin{tabular}{|c|c|c|c|c|c|c|c|c|c|}
\hline \multirow{2}{*}{$\begin{array}{l}\text { Plate/ } \\
\text { Filler }\end{array}$} & \multicolumn{4}{|c|}{ Weld metal } & \multicolumn{4}{|c|}{ Base metal } & \multirow{2}{*}{ Note } \\
\hline & $\mathrm{C}$ & $\mathrm{N}$ & $\mathrm{O}$ & $\mathrm{H}$ & C & $\mathrm{N}$ & $\mathrm{O}$ & $\mathrm{H}$ & \\
\hline $\begin{array}{l}\mathrm{NH} 1 / \\
\mathrm{HP}\end{array}$ & 70 & 97 & 73 & 69 & 60 & 100 & 189 & 86 & $* 1$ \\
\hline $\begin{array}{l}\text { US/ } \\
\text { HP }\end{array}$ & 80 & & 135 & 59 & 120 & 71 & 338 & 51 & $* 1$ \\
\hline NH1/ & 70 & 108 & 198 & 49 & 64 & 105 & 193 & 58 & $* 1$ \\
\hline NH1 & & & & & & & & 1 & $* 2$ \\
\hline $\begin{array}{l}\text { US/ } \\
\text { US }\end{array}$ & & 73 & 355 & 43 & 127 & 57 & 345 & 53 & $* 1$ \\
\hline
\end{tabular}

*1 As-welded, *2 After PWHT at $673 \mathrm{~K}$ for $1 \mathrm{hr}$
Figure 1 shows change in hardness of the weld metal and the base metal of the weld joints after PWHT at various temperature for 1 hour. Hardness level of $\mathrm{NH} 1$ plates and US plates before welds is indicated by a dark zone. Both the weld metal and the base metal was hardened by GTA welding. The hardening of the base metal by GTA welding occurred in all the weld joints at any place examined. After PWHT at $673 \mathrm{~K}$ both the weld metal and the base metal were softened. Hardness of the base metal recovered to the level before welding. From the TEM results, the precipitates observed before welds were dissolved by the welding. Therefore interstitial impurities, such as carbon, nitrogen and oxygen, were expected to be released into matrix and to cause solid solution hardening of the weld metal. On the contrary, no significant change in microstructure was observed by the PWHT at $673 \mathrm{~K}$. The hardness recovery of both the weld metal and the base metal is considered to correspond to the release of hydrogen as shown in Table 1.

The weld metal exhibited hardening again after PWHT at 973 or $1073 \mathrm{~K}$. After the peak, the weld metal was recovered in hardness to the level before welding by PWHT at 1173-1273 K. The hardness of the weld metal increased with increasing oxygen level. From the TEM results in NH1 / NH1 welds, a close correlation was found between the hardness peak and appearance of the fine precipitates at $1073 \mathrm{~K}$. This suggests precipitation dispersion hardening around the hardness peak.

The hydrogen degassing and the softening by PWHT at $673 \mathrm{~K}$ did not change Charpy impact property, while the precipitation hardening by PWHT at $1073 \mathrm{~K}$ induced embrittlement. Ductile-emblittle transition temperature after PWHT at $1073 \mathrm{~K}$ was $277 \mathrm{~K}$, which was much higher than $188 \mathrm{~K}$ obtained at as-welded condition. No improvement of impact property by PWHT is expected at NIFS-HEAT. On the other hand, precipitation behavior during long-time aging and irradiation is expected to determine the performance of V-4Cr-4Ti weld joints, and remains to be studied.

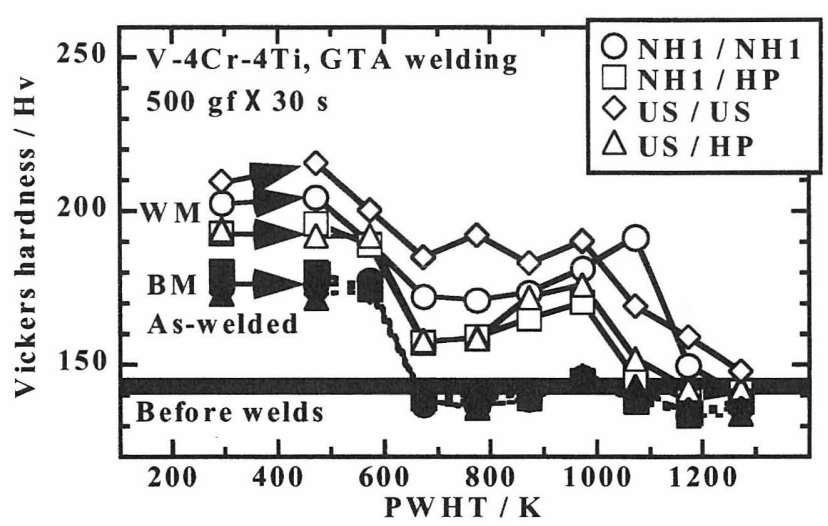

Fig. 1 Change in hardness of the weld metal (WM) and the base metal (BM) after PWHT at various temperatures for 1 hour. 